\title{
Factors influencing the choice of internal medicine as a career among undergraduate medical students
}

\author{
Yamin I. Elzain ${ }^{1}$, Awad Ali M. Alawad ${ }^{2 *}$, Waleed S. Khan ${ }^{1}$, Hassan O. Khalil ${ }^{1}$, \\ Yousif M. Abdelrazig ${ }^{1}$, Omer B. Ahmed ${ }^{1}$, Omeralfaroug A. Adam ${ }^{1}$ \\ ${ }^{1}$ MBBS, Faculty of Medicine, University of Medical Sciences and Technology, Sudan \\ ${ }^{2}$ Assistant Professor, Faculty of Medicine, University of Medical Sciences and Technology, Sudan \\ *Corresponding author E-mail: awadali82@hotmail.com
}

\begin{abstract}
Background: Medical students are the future doctors in any country. The lack or surplus of medical school interest in specialties influences and affects the health services in a country.

Objective: In our study we evaluated the interest of medical students in Internal Medicine at a University in Sudan.

Methods: A cross-sectional study was conducted in September 2013 at Faculty of Medicine, University of Medical Sciences and Technology (UMST), Khartoum, Sudan. A self-administered questionnaire was given to 887 male and female students enrolled at UMST.

Results: A total of 887 questionnaires were handed out, of these 647 questionnaires were returned (response rate of $73 \%$ ). Of the returned questionnaires 604 were valid and considered. Table 1 shows the general characteristics of the valid responses. The majority of our respondents were females $371(61.4 \%)$ and 233 students were males (38.6\%). There were 142 students interested in internal medicine. Of them, $95(21.3 \%$ ) were in pre-clinical years, $47(29.6 \%)$ clinical, $25.3 \%$ were male and $22.4 \%$ were female. Amongst the subspecialties within medicine, $33.1 \%$ of students chose Cardiology as their first choice subspecialty, followed by Internal Medicine (26.8\%), Neurology $(13.4 \%)$ and Dermatology $(11.3 \%)$.

Conclusion: Medicine is second most popular specialty selected by medical students. The highest selected sub-specialty was cardiology. The main reasons for selecting Medicine as a career is personal interest, followed by being helpful to the community, and lastly job opportunities.
\end{abstract}

Keywords: Career Choice, Internal Medicine, Medical Students.

\section{Introduction}

Medical students are the future of any countries Health care system. While it is not the only factor that makes up a health care system doctors are a large part of that system. For example if there is a large surplus in one specialty this could affect how the potential patients are treated. If there is a lack of interest of certain specialties this could severely affect health care to an even greater degree. So, therefore medical student interest in a specialty is an important topic of focus.

Medical students are influenced by many different factors when selecting their specialty and sub-specialty (Abdulghani et al. 2013). One large factor is the medical school curriculum and how much contact or lack thereof they have with certain specialties. At the University of Medical Sciences and Technology (UMST), medical students enter the undergraduate medical programme to hold the Bachelor of Medicine and Bachelor of Surgery (MBBS) degree over a period of five years. Formal clinical training in surgical disciplines takes place during the latter two years, during which time medical students passed through a series of hospital rotations and clinical attachments in the main medical and surgical disciplines.

This study comprises part of an ongoing study of students' career preferences throughout medical school. Considering that the main contact time with clinical science is the fourth and fifth year, those are the years they undertake Medicine rounds and tutorials. This study focuses on medical student interest on Medicine as a career choice. As well as the possibility that may be needed to recruit students into Medicine.

\section{Methods}

A cross-sectional study was conducted from September 2013 to December 2013 at Faculty of Medicine, University of Medical Sciences and Technology, Khartoum, Sudan. A self-administered questionnaire was distributed to 887 students, (from first to fifth academic years) consisting of 13 items, including question related to the demographic variables (age, sex and marital status), questions to identify whether the students have chosen the specialty or not, questions regarding their specialty choices and factors affecting their decision.

The collected data were computerized and statistically analyzed using SPSS (Statistical Package for Social Science) version 19. Descriptive statistics were used to quantify the categorical variables. Chi square was calculated to compare between gender role in specialties and factors affecting specialty choices. $\mathrm{P}$ value $(<0.05)$ was considered significant difference. The ethical approval for this study was obtained from the faculty of Medicine, UMST. An informed verbal consent was obtained from students. 


\section{Results}

The total number of medical students at University of Medical Sciences and Technology is 887.A total of 887 questionnaires were handed out, of these 647 questionnaires were returned (response rate of $73 \%$ ). Of the returned questionnaires 604 were valid and considered. Table 1 shows the general characteristics of the valid responses.

The majority of our respondents were females $371(61.4 \%)$ and 233 students were males (38.6\%). Most of the respondents, 592 (98\%), were unmarried while only $12(2 \%)$ were married. Four hundred and forty five students $(73.7 \%)$ were at preclinical level $\left(1^{\text {st }}, 2^{\text {nd }}\right.$ and $3^{\text {rd }}$ years $)$ and 159 students $(26.3 \%)$ were at clinical level $\left(4^{\text {th }}\right.$ and $5^{\text {th }}$ years $)$. Five hundred and one students $(83 \%)$ had a family member in the medical field while only 103 students (17\%) did not.

Of the respondents 539 students $(89.2 \%)$ had background information about the specialties choice while $65(10.8 \%)$ did not. The most common source of this background information was "Relatives" 282 students (46.7\%) followed by "Internet" and "Friends"; $85(14.1 \%)$ and $75(12.4 \%)$ respectively.

Table 1: The General Characteristics and Other Related Variables of Present Study Participants ( $\mathrm{N}=604)$

\begin{tabular}{lll}
\hline Characteristics & No of Students $(\%)$ \\
\hline \multirow{2}{*}{ Gender } & Male & $233(38.6)$ \\
& Female & $371(61.4)$ \\
Marital status & Single & $592(98)$ \\
& Married & $12(2)$ \\
& 1st year & $157(26)$ \\
Undergraduate Level & 2nd year & $145(24)$ \\
& 3rd year & $143(23.7)$ \\
Family in Medical Field & 4th year & $97(16.1)$ \\
& 5th year & $62(10.3)$ \\
Information about specialty choice & Yes & $501(82.9)$ \\
& No & $103(17.1)$ \\
& Yes & $534(88.4)$ \\
Source of information & No & $70(11.6)$ \\
& Friends & $75(12.4)$ \\
& Relatives & $282(46.7)$ \\
& Internet & $85(14.1)$ \\
& Books & $34(5.6)$ \\
Decision of specialties choice & Workshop & $11(1.8)$ \\
& Others & $52(8.6)$ \\
& Yes & $541(89.6)$ \\
& No & $63(10.4)$ \\
\hline
\end{tabular}

Most of the students have decided upon a specialty $(541,89.6 \%)$ while $63(10.4 \%)$ did not. Chi-square test demonstrated significant relation between gender and future specialties chosen $(p=0.00)$.
Following surgical specialties, subspecialties of Medicine were the second most chosen by students $(142,23.5 \%)$. Bi-variate correlation using spearman correlation test showed no association between undergraduate level and the future specialty chosen $(\mathrm{p}=$ 0.633 ). (Table 2)

Of the respondents who chose a subspecialty of medicine 83 $(58.5 \%)$ were females and $59(41.5 \%)$ were males. Most of the respondents, $140(98.6 \%)$, were unmarried while only $2(1.4 \%)$ were married. Ninety five students $(66.9 \%)$ were at preclinical level $\left(1^{\text {st }}, 2^{\text {nd }}\right.$ and $3^{\text {rd }}$ years $)$ and 47 students $(33.1 \%)$ were at clinical level ( $4^{\text {th }}$ and $5^{\text {th }}$ years). One hundred and twenty two students $(85.9 \%)$ had a family member in the medical field while only 20 students (14.1\%) did not. Of the respondents 127 students $(89.4 \%)$ had background information about the specialties choice while $15(10.6 \%)$ did not. The most common source of this background information was "Relatives" 67 students $(47.2 \%)$ followed by "Internet" and "Friends"; 18 (12.7\%) and $16(11.3 \%)$ respectively. Amongst the subspecialties within medicine, $33.1 \%$ of students chose Cardiology as their first choice subspecialty, followed by Internal Medicine (26.8\%), Neurology (13.4\%) and Dermatology (11.3\%) Figure 1.

Table 2: Shows the Future Specialties Chosen By Students at Pre-Clinical and Clinical Level and Their Corresponding Frequencies and Percentages

\begin{tabular}{llll}
\multirow{2}{*}{ Specialty } & \multicolumn{2}{l}{ Undergraduate Level } \\
& Pre-clinical & Clinical & Total \\
\hline Surgery & $164(36.9)^{*}$ & $36(22.6)^{* *}$ & 200 \\
Medicine & $95(21.3)$ & $47(29.6)$ & 142 \\
Pediatrics & $55(12.4)$ & $20(12.6)$ & 75 \\
Did not decide & $34(7.6)$ & $29(18.2)$ & 63 \\
Obstetrics \& Gynecology & $37(8.3)$ & $16(10.1)$ & 53 \\
Psychiatry & $24(5.4)$ & $2(1.3)$ & 26 \\
General Practitioner & $13(2.9)$ & $0(0)$ & 13 \\
Community Medicine & $8(1.8)$ & $2(1.3)$ & 10 \\
Radiology & $3(0.7)$ & $6(3.8)$ & 9 \\
Forensic Medicine & $5(1.1)$ & $0(0)$ & 5 \\
Basic Sciences & $4(0.9)$ & $1(0.6)$ & 5 \\
Anesthesiology & $3(0.7)$ & $0(0)$ & 3 \\
Total & $445(100)$ & $159(100)$ & 604 \\
\hline
\end{tabular}

* Percentage from total number of students at pre-clinical level

**Percentage from total number of students at clinical level

Figure 2 shows the reasons for choosing a subspecialty within Medicine with their corresponding frequencies. The students were asked to choose the single most compelling reason. The most common reason was "Personal Interest" 51 (35.9\%) followed by "Helpful to the community" 35 (24.6\%) and "Job opportunities" $16(11.3 \%)$.

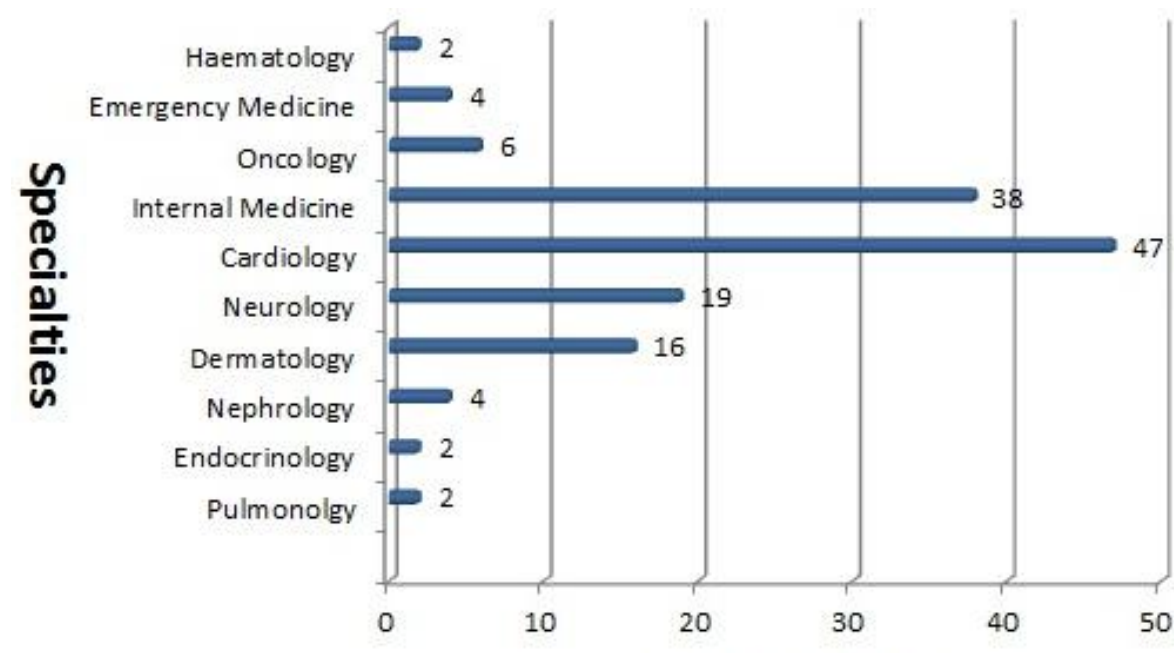

Number of Students

Fig. 1: Shows the Subspecialties within Medicine Chosen by the Students $(\mathrm{N}=142)$ 


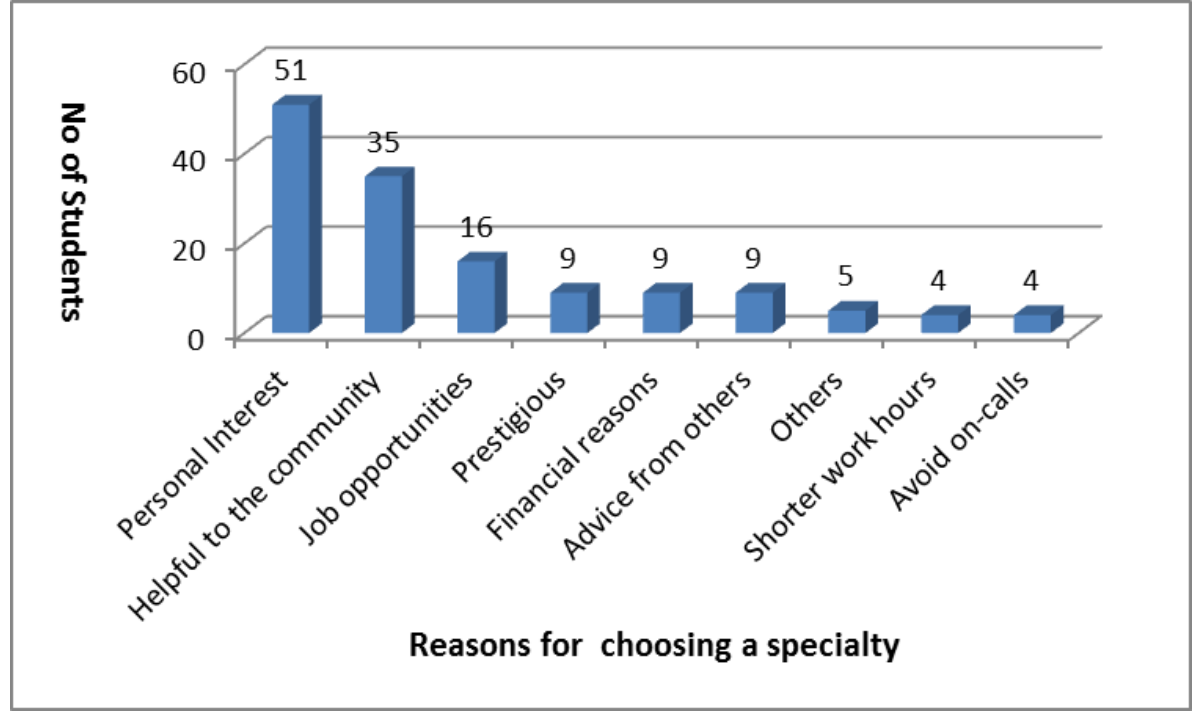

Fig. 2: Shows the Reasons to Choose Medicine as Specialty $(\mathrm{N}=142)$

\section{Discussion}

Several studies evaluated specialty interest among medical students, our study revealed that the most popular specialty is Surgery followed by Medicine. This is synonymous with certain studies such as (Abdulghani et al. 2013, Burch et al. 2011, Chew et al. 2011, Maseghe Mwachaka \& Thuo Mbugua 2010, Rehman et al. 2011, Subba et al. 2012). But other studies revealed a preference in Internal Medicine as being the most popular specialty selected by medical students (Al-Mendalawi 2010, Gibis et al. 2012, Gotz et al. 2011, Mehmood et al. 2012).

The most popular sub-specialties in Medicine are Cardiology (33.1\%), followed by Internal Medicine (26.8\%), Neurology $(13.4 \%)$ and Dermatology (11.3\%). This can reflect the fact that these are the main specialties that are focused on by the curriculum just as reported in a previous study(Julian et al. 2011). As well as the fact that most of the doctors that teach in Medicine are specialized in these areas, keeping in mind that to specialize in Cardiology for example, a doctor must also specialize in Internal Medicine(Al Kadri et al. 2012).

The most popular sub-specialties selected by medical students may be influenced by role models that teach in those subspecialties. While role models don't advice students to pursue subspecialties the approach to teaching and the manner in which they teach students has an influence on the students' perception of a sub-specialty (Blue et al. 1996, Wright et al. 1997, Zborovski et al. 2010).

In our study the factor which played the biggest role in specialty selection is personal interest followed by being helpful to the community. This is contrary to other studies where prestige, interpersonal issues, intellectual content, anticipated income, and work hours are the commonest factor for specialty selection (Babbott et al. 1991, Creed et al. 2010, Flynn et al. 1993, Gorenflo et al. 1994).

When medical students select their specialties based on many different factors and are influenced in many ways. One of the main influences is the medical school curriculum and how much contact time those students spend in any discipline. So for example, if a medical school curriculum mainly consists of surgical clinical rotations this may have a large influence on student specialty selection (Burke et al. 1994, Linzer et al. 1994, Peccoralo et al. 2012). Any lack in doctors in internal medicine may be solved by giving medical students more influence by altering medical school curriculum.

\section{Conclusion}

Internal medicine is the second most popular specialty among medical students in our study. There are many factors for selecting specialties but the commonest one in our study is personal interest. These factors can be used by mentors of medical students to motivate students to choose medical specialties that are scarce in $\mathrm{Su}$ dan and therefore better serve the community. The sub-specialty which draws the most interest among medical students is Cardiology.

\section{References}

[1] Abdulghani HM, Al-Shaikh G, Alhujayri AK, Alohaideb NS, Alsaeed HA, Alshohayeb IS, Alyahya MM, Alhaqwi AI \& Shaik SA (2013): What determines the selection of undergraduate medical students to the specialty of their future careers? Med Teach 35 Suppl 1, S25-30.

[2] Al-Mendalawi MD (2010): Specialty preferences of Iraqi medical students. Clin Teach 7, 175-179.

[3] Al Kadri HM, Al-Moamary MS, Tamim HM \& Al-Kadi MT (2012): Value of subspecialty experience in internal medicine undergraduate training. Saudi J Kidney Dis Transpl 23, 545-551.

[4] Babbott D, Levey GS, Weaver SO \& Killian CD (1991): Medical student attitudes about internal medicine: a study of U.S. medical school seniors in 1988. Ann Intern Med 114, 16-22.

[5] Blue AV, Donnelly MB, Harrell-Parr P, Murphy-Spencer A, Rubeck RF \& Jarecky RK (1996): Developing generalists for Kentucky. $J$ Ky Med Assoc 94, 439-445.

[6] Burch VC, McKinley D, van Wyk J, Kiguli-Walube S, Cameron D, Cilliers FJ, Longombe AO, Mkony C, Okoromah C, Otieno-Nyunya B \& Morahan PS (2011): Career intentions of medical students trained in six sub-Saharan African countries. Educ Health (Abingdon) 24, 614.

[7] Burke W, Baron RB, Lemon M, Losh D \& Novack A (1994): Training generalist physicians: structural elements of the curriculum. $J$ Gen Intern Med 9, S23-30.

[8] Chew YW, Rajakrishnan S, Low CA, Jayapalan PK \& Sreeramareddy CT (2011): Medical students' choice of specialty and factors determining their choice: a cross-sectional questionnaire survey in Melaka-Manipal Medical College, Malaysia. Biosci Trends 5, 69-76.

[9] Creed PA, Searle J \& Rogers ME (2010): Medical specialty prestige and lifestyle preferences for medical students. Soc Sci Med 71, 10841088.

[10]Flynn TC, Gerrity MS \& Berkowitz LR (1993): What do applicants look for when selecting internal medicine residency programs? A comparison of rating scale and open-ended responses. J Gen Intern Med 8, 249-254.

[11]Gibis B, Heinz A, Jacob R \& Muller CH (2012): The career expectations of medical students: findings of a nationwide survey in Germany. Dtsch Arztebl Int 109, 327-332. 
[12]Gorenflo DW, Ruffin MTt \& Sheets KJ (1994): A multivariate model for specialty preference by medical students. J Fam Pract 39, 570576.

[13]Gotz K, Miksch A, Hermann K, Loh A, Kiolbassa K, Joos S \& Steinhauser J (2011): [Aspirations of medical students: "planning for a secure career" - results of an online-survey among students at five medical schools in Germany]. Dtsch Med Wochenschr 136, 253-257.

[14]Julian K, Riegels NS \& Baron RB (2011): Perspective: Creating the next generation of general internists: a call for medical education reform. Acad Med 86, 1443-1447.

[15]Linzer M, Slavin T, Mutha S, Takayama JI, Branda L, VanEyck S, McMurray JE \& Rabinowitz HK (1994): Admission, recruitment, and retention: finding and keeping the generalist-oriented student. SGIM Task Force on Career Choice in Primary Care and Internal Medicine. J Gen Intern Med 9, S14-23.

[16]Maseghe Mwachaka P \& Thuo Mbugua E (2010): Specialty preferences among medical students in a Kenyan university. Pan Afr Med J 5, 18.

[17]Mehmood SI, Kumar A, Al-Binali A \& Borleffs JC (2012): Specialty preferences: trends and perceptions among Saudi undergraduate medical students. Med Teach 34 Suppl 1, S51-60.

[18]Peccoralo LA, Callahan K, Stark R \& DeCherrie LV (2012): Primary care training and the evolving healthcare system. Mt Sinai J Med 79, 451-463.

[19]Rehman A, Rehman T, Shaikh MA, Yasmin H, Asif A \& Kafil H (2011): Pakistani medical students' specialty preference and the influencing factors. J Pak Med Assoc 61, 713-718.

[20]Subba SH, Binu VS, Kotian MS, Joseph N, Mahamood AB, Dixit N, George A, Kumar P, Acharya S \& Reddy P (2012): Future specialization interests among medical students in southern India. Natl Med J India 25, 226-229.

[21]Wright S, Wong A \& Newill C (1997): The impact of role models on medical students. J Gen Intern Med 12, 53-56.

[22]Zborovski S, Rohekar G \& Rohekar S (2010): Strategies to improve recruitment into rheumatology: results of the Workforce in Rheumatology Issues Study (WRIST). J Rheumatol 37, 1749-1755. 